\title{
Data Entry and the Economy of Offshore Information Production
}

\section{Steven Ellis}

\begin{abstract}
In this article a review of the data-entry industry and the role information organizations, such as libraries, play in that industry is presented. Information organizations are participants in an economy of information production-one that is becoming globalized. With this globalization, new production practices have emerged. However, research has been accumulating for some time that calls the labor practices of the data-entry industry into question. With these labor practices come ethical dilemmas for information professionals. It is therefore necessary for the information professions to come to an understanding of this emerging economy. It is argued that an ethics of data conversion can neither arise through ceasing production offshore nor from technological advances in data-entry technology. An ethics of information production must involve the cooperation of both producers and consumers alike.
\end{abstract}

I

formation systems are designed to permit ease of use, not to reveal their origins. Yet information that is "electronic" by necessity has to get into the machine in some way. Often this process is referred to as "data entry." It is the purpose of this paper to look at how data entry has often come to be accomplished, to consider the appropriateness of this situation, and to determine the need for ethical standards to guide decision making in the acquisition of converted data.

There is no single solution to the problem of data entry. Every document and project presents challenges to conversion. Not only must decisions be made about database and document structure, decisions must also be made about the means of production and the use of conversion technologies such as imaging, optical character recognition, or manual keyboarding. Decisions about the means of data entry have been made about many of the thousands of electronic products currently in the information marketplace.

For all that has been written about digitization trends, we have seen comparatively little on how and where information is produced when it is converted to electronic formats. In addition, there has been very little or no treatment in the literature on the ethical obligations of information professionals who purchase electronic information on behalf of their constituencies. This represents a significant gap.

In pursuing conversion strategies, two factors have often been key: cost and data integrity. Lower costs are often sought as long as quality is maintained. In this process, "outsourcing" might emerge as a production option. In outsourcing documents, a library, publisher, or vendor can "go offshore" in pursuit of lower data-

Steven ElLis (sre@psulias.psu.edu) is Electronic Text Librarian, University Libraries, Pennsylvania State University. Manuscript received October 18, 1996; accepted for publication January 17, 1997. 
entry costs. The research surveyed here indicates that the consideration of cost and data integrity alone might not adequately account for needs in all sectors of the data-entry economy, however. Like other industries that participate in a global economy, such as garment manufacturing, the data-entry industry often shows the signs of gender discrimination, work-related health problems, and the sorts of quick changes in location by production firms that leave local areas no better off than they were prior to the firm's arrival. It is argued here that a third factor needs to be introduced into the data-conversion system: an ethical framework that both would ensure adherence to fair and equitable practices in data production and guide information professionals in their purchasing decisions.

Within the global economy, there are systems of regulation that might provide useful examples in understanding the ethical requirements of the data-entry economy. The garment industry has been subject to a number of checks and balances in order to ensure that production firms meet their liability to their workers. For example, U.S. clothing manufacturers are subject to a combination of regulatory measures, some that originate from within the company, some from international trade agreements, and some from international public law. Such regulatory environments would not be possible without predefined ethical standards stemming from perceived needs. News media and industry experts play a role by focusing public attention on problems, and consumers play a role by making purchasing decisions based on perceptions of the industry.

It is the goal of most information organizations (such as libraries) to provide seamless, transparent information access for a constituency of users. As more information organizations consider low-cost solutions for converting large portions of their collections to electronic formats, the importance of supporting an ethics of information production and consumption grows. Certainly this importance is already upon us as most well-financed information organizations acquire an array of electronic products with little sense of how they were produced. It is argued that without a thorough understanding of the conditions of information production, access organizations could be participants in the perpetuation of inequalities their values might not permit.

\section{OfFShORE DATA ENTRY}

Libraries and other information organizations participate in a global economy of information production. Just as going offshore for data-entry services has become an option available as a means to reduce costs for libraries, publishers, and vendors, so providing data-entry services has become one way for less developed countries (L.DCs) to attract foreign investment. In many LDCs, foreign corporations find a flexible, skilled, and semiskilled labor force at wage rates that would be 6 to 12 times higher in the United States (Office of Technology Assessment [OTA] 1985). Foreign information organizations might require a number of data-entry or data-processing services, often involving the conversion of printed materials to electronic formats. These materials might include anything from airline ticket stubs to library catalogs. Publishers and online data services companies are targeted by data-entry firms for their long-term potential for growth and perhaps represent an even more viable market than more traditional offshore clients such as the insurance industry (Posthuma 1987). It would seem that as the demand for electronic data increases so will its production offshore.

Many LDCs see in this burgeoning market both a short-term opportunity to provide jobs for their citizens and a longterm opportunity to promote fledgling microcomputing industries, a process referred to as "technology transfer" by development experts. When technology transfer occurs, technologies that require less skill might be replaced by those requiring greater skill. For example, routinized work such as semiconductor manufacture might give way to more highly skilled work such as authoring software. While the number of jobs might rise dramatically with the introduction of routinized work performed for foreign firms, 
technology transfer does not always occur as planned, although it remains a goal for local planners, development experts, and economists seeking to develop skilled industries. Unfortunately, the research reviewed here indicates very little evidence for technology transfer in the data-entry industry.

With regard to existing jobs and labor practices, data-entry firms, both foreign and locally owned, are often in the position of perpetuating poor labor conditions. Each study examined here brings into focus two characteristics that deserve detailed attention: (1) data-entry workers often suffer from work-related health problems, and (2) data-entry workers are often the object of gender discrimination.

The vast majority of data-entry operators are women who, not coincidentally, are offered little opportunity for advancement. The kinds of skills a data-entry operator acquires might have little application in other jobs, especially those that provide higher pay and more responsibility (Pearson and Mitter 1993). This pattern of gender-based hiring-combined with a lack of mobility or opportunity for the acquisition of skills-is what Haraway, and others following her, have called the Informatics of Domination (Haraway 1991).

In addition to often being the object of gender discrimination, data-entry operators often suffer from many of the same physical and psychological ailments associated with traditional offshore manufacturing, such as the much-criticized garment industry. For example, in Brazil, the data-entry industry is promoted locally as the "profession of the future"; however, Brazilian data-entryworkers suffer from a variety of physiological disorders, including a high incidence of musculoskeletal diseases, fatigue, and depression (Sores 1991). However unfortunate it might sound, these women have become the drones or "feeders" of the global information economy (Posthuma 1987).

My purpose in this paper, then, is to provide an ethical framework that would account for inequalities of the data-entry system through the responsible acquisition of converted data. This framework would not be possible, however, without a more complete understanding of the requirements of a global economy and the conditions of information production as that production occurs in LDCs.

\section{THE RequiRements of A GLOBAL ECONOMY}

As economies become interdependent, new regulatory systems emerge. These regulatory systems have ethical components, some with regard to labor. Yet, as De George (1993) notes, the global economy currently lacks adequate background institutions, unlike many nation-states. Background institutions are those bodies of legislation and regulation that would codify acceptable standards and practices in the general interest of interdependent nation-states. In the absence of truly international background institutions, industries are regulated by a combination of the laws and standards where products are produced, as well as by the laws and values of countries where products are consumed.

A number of U.S. trade laws reflect and attempt to manage this interdependence with regard to labor issues. For example, in the United States the Generalized System of Preferences (GSP) allows certain domestic products to be exported duty-free to designated "beneficiary developing countries." In order to be included in the program, a developing country must take or have taken "steps to afford internationally recognized worker rights to workers in the country (including any designated zone in that country)" (Trade Act of 1974 , sec. 2462[b][7]). Worker advocates have used the petition process within the GSP frequently to challenge a given country's inclusion in the program as a means to support workers' rights (Ho, Powell, and Vlopp 1996).

The internationally recognized rights specified within the GSP have bearing on offshore data entry insofar as they demonstrate a framework within U.S. law for ethical responses to international matters. According to the standards defined in the GSP, workers have the right to associate freely, to organize, and to bargain collectively-these in addition to prohibitions against slavery and low wages for children. 
Workers also are entitled to "acceptable conditions of work with respect to minimum wages, hours of work, and occupational safety and health" (Trade Act of 1974, sec. 2462[a][4]) - provisions that have direct bearing on the problems particular to the data-entry industry. Whatever the industry, however, the recognition of such universal rights provides a baseline for forming ethical responses to labor inequalities in a global economy.

An ethics of information production would therefore include a set of minimum acceptable practices for the data-entry industry and for information professionals. This would include both the material requirements of the information economy (the inevitable need for more data) while it would include a consideration of both the local economies and the employment needs of data-entry operators. These minimum ethical standards might be integrated into existing codes and practices by which information professionals conduct their business of vending or buying electronic data.

\section{UNDERSTANDING THE DATA-ENTRY ECONOMY}

Geographers have witnessed for some time the trend that information is being exchanged over greater distances (Hepworth 1990). The globalization of consumer markets, trade deregulation, and advances in telecommunications have contributed to an increased interdependence among nations and the emergence of extranational entities, such as transnational corporations (TNCs). Such corporations are now able to consider global strategies in markets, investments, and in the quest for cheap labor-a trend globalization experts have come to refer to as "capital and labor flexibility." Many information organizations frequently contract with corporations that show the signs of TNC flexibility, either directly or through subsidiaries.

With the emergence of TNCs in mind, the history of data entry is best understood through the history of back-office operations. Since the 1950s, with the introduction of office computer applications, high- volume and repetitive data-processing activities have been consolidated and moved to areas where costs are lower (Nelson 1986). Throughout the 1980s, certain U.S. firmsmany in the airline and insurance industryestablished offshore bureaus for the purpose of performing manual clerical work at a lower cost. In the case of American Airlines, for example, this included the establishment of a wholly owned subsidiary, Caribbean Data Services (CDS), to process its data-entry needs. Over time, CDS has proved so profitable that it now contracts its services outside the corporation. CDS recently opened a U.S. $\$ 10$ million data-entry plant in Barbados employing 1,500 people (Pearson 1993). Similar success stories abound. For example, Hamilton (1990) presents a popular account of Saztec, a foreignowned data-entry firm with production facilities in the Philippines.

The success of data-entry firms would not be possible if it were not so easy to exchange labor in one area for labor in another. Such rapid and frequent changes in location worry development experts. When considering the prospects for an abandoned area, Posthuma (1987, 62) writes that former hosts are left with "nothing more substantial than a few trained keyboard operators, and an abandoned factory shell with the empty electrical outlets, which formerly powered the data entry terminals." In Grenada, when unsettled conditions arose in the early eighties, the back-office operation of a large American accounting firm (Coopers \& Lybrand) relocated quickly (OTA 1985).

The ease with which labor in one area might be exchanged for labor in another is not unlike corporate restructuring in the United States, where whole service bureaus have been relocated from urban areas to suburban ones, again to take advantage of cheaper labor. Hostcountry policy often facilitates this style of corporate mobility in the form of incentives like those offered in Jamaica's Montego Bay Free Zone, including lowcost facilities, tax benefits, and the right to repatriate all profits and dividends to the home country (International Labor Organization 1990). Free zones are de- 
signed specifically to attract foreign capital and sometimes have little effect on local economies, other than to benefit elites. In Jamaica, as of 1993, 5 of the 25 data-entry firms were U.S.-owned subsidiaries or U.S.-Jamaican joint ventures. A new generation of black entrepreneurs owns and manages the remaining firms, although all but three of these firms operate outside of the free zone and are thus unable to pass on to clients the benefits foreign firms can. In the Dominican Republic, Barbados, and St. Lucia, almost all of the data-entry operations are foreignowned and are believed to be operating within free zones (Pearson 1993).

Advances in telecommunications increase the degree to which areas can compete with one another for foreign capital (Warf 1995). A hard-copy insurance claim might be sent to the host country from New York by mail or overnight air. Once the data are processed, they might be beamed back via satellite or leased fiberoptic line. However, the temptation to account for rapid changes in location by reference to what technologies make possible must be resisted. The burden for such decisions must be placed on host countries, the transnational firm producing or vending the information, and the companies and individual organizations purchasing the information for subsequent sale to libraries and other information organizations. Information professionals have a role to play throughout this process by both identifying the underlying ethics within their profession and using those ethics to define guidelines for the production and acquisition of electronic information.

\section{Tracing Documents}

It is difficult to trace when and where documents are converted to an electronic format case by case. Most electronic documents show no sign of manual data entry and certainly never reveal anything that might indicate something so specific as country of origin. None of the product tracing performed on clothing manufactured in sweatshop conditions has been done with regard to electronic documents.
In the information profession, anecdotal evidence points to a general lack of awareness about how documents are converted. "I didn't know" was the reaction of one librarian in charge of a data-conversion project when told by a reporter about the data-entry firm with whom the library had contracted-even in this case when the firm was domestic and employing workers in a monastery (Young 1996). While working conditions in this case might be favorable, the example illustrates a general lack of awareness of how electronic products are made, by whom, and under what conditions.

Finding out about the conditions of production for firms offshore presents its own difficulties. Like the tips of organizational icebergs, many firms that provide document-conversion services have small bureaus located in developed countries in order to transact business with their clientele, whereas the vast majority of their operations are located in less developed host countries. On the whole, information professionals need to be aware of the way in which certain institutions within the data-entry industry make the practices of data entry hard to see.

\section{WOMEN, SKILLS, AND WORK}

Despite the difficulties in tracking labor practices, in some LDCs conditions have been well documented. Each situation shows striking similarities in job-related health problems and routine polarizations of skill and gender. Both features of the data-entry economy are generally considered by development experts to be undesirable outcomes of employment in any country.

In contrast to the mobility of the TNC, the opportunities available to the data-entry operator are few. Many of the free zones where foreign-owned data-entry operations are located do not allow unionization as part of their charter (Pearson and Mitter 1993). The number of people affected is high. Sores (1991) reports that data-entry operators make up $36.2 \%$ of the information work force in Brazil. The author further outlines the situation there: There are three shifts for data-entry 
operators in São Paulo. Workers are evaluated according to their production rates and pace of work, which, like many dataentry operations, is electronically monitored. Fifty percent perceived that their health had worsened since they began to work with video display units (VDUs). Eighty percent complained of general tiredness; $54 \%$ of headaches. There was a high incidence of musculoskeletal disorders of the arms, shoulder and neck area, back, and legs. According to the medical statistics of the organization surveyed, 17 operators had been diagnosed as having tenosynovitis, of whom five had to be permanently moved to other kinds of work. So as not to leave any doubt about the demands of such levels of productivity, Sores concludes with this remark gathered from a data-entry operator: "Whoever looks at us from outside can perceive that we are in the slavery age, working as a slave and being whipped, not in our bodies, but in our minds" (p. 1223). Likewise, in Malaysia, $\mathrm{Ng}$ and Othman (1991) reported a survey undertaken in 1990-91 of 216 data-entry operators; their survey revealed a high incidence of eye problems (affecting over half), disorders of the hands and wrists $(46.7 \%)$, and of the shoulders, neck, and back (33.3\%).

Although there is little documentation on keyboarding-related health problems in Jamaica, Pearson and Mitter (1993, 50) make the situation plain: "[I]n terms of pay, conditions of work, opportunities for promotion, security and longevity of employment, this sector does not perform any better than the garment factories in Kingston's free zone." Other regions that are known to have fairly extensive data-entry operations include Mexico, the Philippines, Singapore, St. Lucia, St. Christopher-Nevis, St. Vincent, India, and Ireland.

Unsafe working conditions are not restricted to LDCs. It has been reported, for example, that Japanese data-entry operators complain of electronic surveillance, restrictions on physical mobility, high levels of exhaustion, and dissatisfaction with nature of the work. In a survey of over 13,000 conducted by the General Council of Trade Unions (Sohyo), Shiga (1987) found a higher rate of pregnancy abnor- malities among women who spent long hours with VDUs. The author also found a link between VDU work and psychological disorders, including depression, abnormal eating habits, and alcohol dependency.

The kinds of skills a data-entry operator acquires might have little application in other industries. This contributes to skill polarization, or the segmentation of the labor force into a small class of highly skilled systems analysts, programmers, and related occupations on the one hand and, on the other, a group of clerical and related jobs, which includes data-entry workers (Pearson 1993). Based on the surveys in Malaysia, Jamaica, and Brazil, clerical jobs outnumber technical ones by about ninety to one (Pearson 1993). The practice of body shopping exacerbates this fragmentation. In shopping for bodies, transnationals strip out the highly skilled LDC workers (mostly men) by transporting them from their home country to the clients' place of work to take advantage of superior hardware and alleviate any "lack of trust" a worker in a distant location might incur (Pearson 1992). For example, Indian workers provide as much as $80 \%$ of software services to clients on-site overseas. In a similar way, a general pattern with foreign-owned data-entry firms is that high-skill jobs are filled by personnel under the control of the foreign firm, rather than filled by local personnel (Posthuma 1987). This practice does little to contribute to the host country's economy, because healthy local economies by necessity require the community and salary input of more highly skilled and higherpaid workers.

Skill polarization cannot be understood without recourse to the division of labor by gender. Up to $98 \%$ of those employed in the data-entry sector are women. This does not signify an opportunity, however. Instead, women are often considered to be a source of cheap labor and are given positions that require a minimum of skills. Each of the studies surveyed here points to a form of gender bias that perpetuates a closed cycle: dataentry women are locked into physically damaging work with little or no opportu- 
nity for making transitions to traditionally male (and increasingly scarce) technical or supervisory roles. As one manager of a large data-entry facility put it: "Women are better at this kind of job. They are more dexterous, more disciplined, more caring about the quality of work and more agile" (Barnes 1989, 18).

The more disciplined, dexterous, and dependable an operator is, the longer she can stay at the machine, and the higher her productivity will be-a gender role that easily legitimates the very sorts of production practices that have proved problematic. Discrimination of this kind is something no amount of worker safety and ergonomics will resolve.

\section{Technological Solutions?}

In spite of the growth of the offshore data-entry economy, some will argue that the technology exists now, or will one day soon, to eliminate the need for what those in the ergonomics and productivity industry call the "human factor." This technology falls under the rubric of optical character recognition (OCR). OCR has been in existence in its most basic form for roughly thirty years and only within the last ten has achieved accuracy rates that under some circumstances are equivalent to manual keyboard entry. Yet, however unfortunate it might be, there are good reasons why the conversion of printed documents to an electronic format will for the foreseeable future require substantial human intervention. Human operators are needed not only for less routinized tasks, such as error correction and general editorial work; the process will very likely continue to demand extensive manual repetitive operations as well.

As an example, Saffady (1995) argued recently that OCR technology represents an alternative of much lower (monetary) cost to manual offshore data entry. These figures are based on very large-scale, and at this point hypothetical, library digitization projects costing more than U.S. \$1 million. However, with projects of this scale, offshore costs and OCR are roughly equivalent when OCR completion times are reduced to 1 year from 2.5 , increasing the number of workstations needed to begin work. This means that in smaller-scale projects, OCR costs will continue to outstrip offshore costs due to the need for high initial expenditures on hardware. In contrast, most offshore data-entry jobs are routinely of a smaller scale (Pearson and Mitter 1993).

All of this assumes that OCR technology is an effective means for document conversion, which might contradict the experience of those involved in large- and small-scale conversion projects over the years. According to Olsen and McLean (1993), OCR is more costly for large-scale conversion projects. Olsen has presided over the conversion of more than $120 \mathrm{mil}$ lion words of Erench primary sources. OCR costs more because documents produced in this way require extensive postproduction editing to correct those errors initially produced by the machine. Manual keyboarding simply reduces the number of errors by introducing the human element at the beginning of the process rather than the end. When asked about the utility of OCR technology, the Conversion Coordinator of the National Digital Library Project recently told a reporter for American Libraries: "The human being is a more effective device" (Backstage 1996, 27).

OCR is less effective than keyboarding not only due to the number of machineproduced errors. There are things OCR simply cannot do. All documents have elements that by nature require manual keying simply because they have little physical presence within the document that the OCR software can recognize. Consider an average monograph as an example. For the document to have its full functionality in its electronic version, elements such as headings, page numbers, and footnotes must be specified with metadata. This metadata must be manually keyed. Database designers also might add a number of metadata elements to aid retrieval.

As digitization proliferates, so will the complexity of documents. I would not like to suggest that OCR will never work, or even that it has not been used effectively in certain projects. The fact remains, however, that it has not been widely used and 
most likely will not be used in conversion projects for some time. From this perspective, the uncritical affirmation of OCR technology by information professionals and industry spokespersons might serve the purpose of diverting attention from routinized low-technology operations by relegating them to a thing of the past.

\section{Toward an Ethical Standard}

As information organizations become driven by the imperatives of zero-sum management and outsourcing becomes commonplace, the increased export of routine processes offshore would seem inevitable. By the middle $1980 \mathrm{~s}$, the Library of Congress had already experimented with such a strategy with its Overseas Operation Division (Kniskern 1986). There needs to be a greater awareness within the information profession of the economy of information production. It has been suggested that the global economy is susceptible to exploitative production practices. With this in mind, I believe an ethics of information acquisition is required. The information professions are in a unique position to shape the development of the data-entry economy through ethically informed decision making. For example, librarians developing collections might consider the means of production as one evaluative criterion for the electronic information they acquire.

But why ethics? As a field of study, ethics is concerned with the moral choices made by individuals in relationship with other choices. Professional ethics are the rules or standards that govern the conduct of the members of a profession, of which the most well known are those included in the Hippocratic Oath adopted by physicians worldwide. In a similar way, the Association for Library Collections \& Technical Services (ALCTS) supplement to the American Library Association Code of Ethics reads that an ALCTS member both "strives to provide broad and unbiased access to information," as well as "fosters and promotes fair, ethical and legal trade and business practices" (ALCTS, Acquisi- tion Section, 1995). This general statement makes explicit what many have always assumed is their ethical responsibility as librarians and information professionals. Such written codes of conduct can be helpful, although in order to be useful ethics must be put into practice as context-specific problem-solving tools.

Ethics often operate behind our everyday actions. Understanding the ethics that underlie daily practice in the field can assist in formulating an approach to the data-entry industry. Within the information professions, an emphasis is often put on access to information without barriers - as well as on the principle of intellectual freedom for authors and readers alike. Librarians purposefully select information resources to represent all sides of controversial issues and offer information services that assist people in finding what they need without charging for each use. These moral values and principles are subsequently upheld in the everyday actions of information professionals taken on behalf of users. Similar professional values and standards might be brought to bear in developing ethical tools to assist daily decisions in the acquisition of electronic information.

\section{An Ethical Framework}

If the conditions of offshore data entry often conflict with the values of information professionals, the question becomes how we might enable ethical decision making in the purchase of electronic products. Such decisions will demand specific kinds of documentation on the conditions of data production-documentation that would allow information professionals to know whether a given product was produced in accordance with accepted labor practices and standards, and not in a data-entry sweatshop. The requirement of such documentation would have the added function of bringing production firms into compliance with acceptable standards and practices. Three problems have been isolated with regard to the data-entry industry. Each problem requires a specific kind of documentation. 
1. Data-entry operators are at risk with regard to work-related health problems. The working conditions of dataentry operators must be documented when a given unit of information is produced. Data might include level of health benefits, how workers are paid (by keystroke or hourly), and incidence of musculoskeletal disorders.

2. Data-entry operators are often the object of gender discrimination. The existence or lack of firm-sponsored programs intended to allow data-entry operators to transfer their skills to higher levels of responsibility must be documented.

3. Features of the data-entry economy make tracing a given information unit to its origin difficult. Written proof of place of origin (country, city, or zone within either) must be available for electronic products. If parts of a given product have been produced in different locations, each must be documented. The length of time a firm has been in its current location might also be documented.

Each of these forms of documentation would provide the means for information professionals to respond ethically when making purchasing decisions. It remains to be seen, however, what agency or agencies would be responsible for the form and accuracy of documentation. In this regard, both the garment and the forestproducts industries furnish examples of international regulation from which we might learn.

In the garment industry, no single system of regulation has emerged. Ho, Powell, and Vlopp (1996) outline the range of systems currently in place. Many production firms in the garment industry, both foreign and domestic, change location rapidly. Such operations are sometimes unable to meet their liability to their workers even in the most basic way-in terms of safety and pay. Even though most laws are limited to the United States, there are several options available to prosecutors when problems emerge internationally. These include applying U.S. law internationally; using public international law or U.S. trade law; and writing labor stand- ards into international trade agreements such as NAFTA and GATT. In addition to these formal legal strategies, extralegal strategies include voluntary codes of conduct (corporate, union, and those arising from community organization); worker organizing; consumer strategies; and activist advocacy. Unfortunately, due to the complexity of the global economy, no single strategy is effective all of the time, and most ultimately lack teeth in a global context. However capricious they might be, when consumer awareness and media attention have been focused on the garment industry, they have served to galvanize the effective use of existing statutes-indicating that those outside the industry can have an effect.

Information professionals are a professional group guided by common ethics and goals. This common ground might be effective in setting goals for or partially performing the function of a background institution in accordance with $\mathrm{De}$ George's (1993) prescription. Collection development officers often make decisions about the purchase of large quantities of electronic information, and can take the means of information production into account when making collection decisions that might have a direct effect on the industry.

Another example that might be particularly useful with regard to implementing standards for data entry can be found in the forest-products industry. In order to sustain biodiversity-as well as maintain forests for future timber production-trees that originate from ecologically managed forests are now often certified and marked accordingly (Sugal 1996). The background institutions in this case are numerous, consisting of both third-party and national initiatives. When firms regulate themselves, Sugal warns, a "greenwashing" might occur. There is now a widespread demand for certified timber-roughly one-third of the market. However, it has been more difficult to reach individual timber consumers, whose primary considerations remain cost and quality. Certified timber is often purchased by organizations bound by ethical standards in purchasing, such as when 
lumber is acquired for public housing. In this case, urban planners and city governments have come to a consensus that an ethics of building in the public interest requires ecologically produced lumber.

Similar systems might be effective in working with the data-entry industry. The importance of involvement from information professionals cannot be underestimated. Until such systems are in place, information professionals could request documentation from their vendors independently. The obvious difficulty here is that evaluation of such documentation is likely to be difficult at best and more likely not always meaningful. However, by requesting documentation from vendors now, the information profession can alert vendors to what the profession considers important and begin to influence the development of a data-entry industry in accordance with long-term objectives: good working conditions for employees and the promotion of sound, sustainable economies based on appropriate mixes of skilled and unskilled labor.

\section{SUMMARY}

Information organizations such as libraries are actively engaged in the acquisition and dissemination of electronic data. This practice will most likely continue to grow as more collections are converted to electronic formats and acquired in electronic formats. Two factors have traditionally been associated with the conversion of printed materials: cost and data integrity. In this process a third factor has been neglected: the labor conditions under which conversion occurs.

The global economy is prone to inequalities. Features of the global economy include increased interdependence among nationstates, increased competition for cheap labor (among free zones, for instance), and labor abuses. Each of these features has affected the economy of data entry. Data entry is routinely performed offshore in order to reduce costs, data-entry firms often rapidly change location when local costs become too high, and data-entry operators are often the object of work-related health problems and gender discrimination.
Such conditions require an ethical response that accounts for the needs of both producers and consumers. In addition to ethical baselines defined within U.S. law pertaining to worker rights, there are ethical precedents within the information profession, as in the support of access, intellectual freedom, and the representation of diverse views. Principles such as these might be extended to the support of ethical data conversion.

Of the models of regulation surveyed, the kinds of certification and marking as currently carried out in the timber industry might be the most appropriate for electronic information. In addition to making the point of origin of a given unit of information ascertainable at any given time, such a system would perform two functions: (1) in order to be certified, the industry would have to comply with internationally defined labor standards, and (2) consumers within the information professions could be confident that a given electronic product was produced in accordance with those international standards and the ethics of their field. Data marking could very well embody an ethics that accounts for both producers (data-entry operators and owners) and consumers (information professionals and end users).

While OCR might one day present certain limited solutions, it (1) has not yet been widely been used, (2) is considered by practitioners to be ineffective, (3) has costs that are potentially higher for small-scale projects, and (4) does not easily allow for the encoding of metadata elements. Uncritical affirmations of OCR technologies might serve to overshadow the prevalence of lowtechnology operations.

It would be reckless to suggest that all electronic information produced offshore is done in an unethical manner. Nevertheless, when the nature of the global economy and its susceptibility to abuses are taken into account, it is hard to underestimate the importance of an ethical approach (on the part of information producers and consumers) that supports equitable conversion practices. Increased digitization and information flow, while perhaps being the condition of networks, financial markets, etc., come at a price rele- 
vant not only to individuals in the business of providing access or their constituents. The economy of electronic information directly affects the lives of those at a distance from privileged areas where access projects are possible.

\section{WORKS CITED}

ALCTS, Acquisitions Section. 1995. Statement on principles and standards of acquisitions practice (1994). Available gopher: gopher://ala1.ala.org:70/00/alagophxiii/ alagophxiiialcts/alagophxiiialctsethics/ 50714036.document.

Backstage at the cybrary. 1996. American libraries (Mar. 27): 33.

Barnes, Corienne. 1989. Data entry demands. Sistren 11, no. 3: 18-22.

De George, Richard. 1993. Competing with integrity in international business. New York: Oxford Univ. Pr.

Hamilton, John Maxwell. 1990. Entangling alliances. Cabin John, Md.: Seven Locks.

Haraway, Donna J. 1991. Simians, cyborgs and women: The reinvention of nature. London: Free Association.

Hepworth, Mark E. 1990. Geography of the information economy. London: Guilford.

Ho, Laura, Catherine Powell, and Leti Vlopp. 1996. (Dis)assembling rights of women workers along the global assembly line: Human rights and the garment industry. Harvard Civil Rights-Civil Liberties Law Review 31: 383-414.

International Labor Organization. 1990. Conditions of work digest 9 , no. 1 .

Kniskern, Alice L. 1986. Overseas data entry. Information technology and libraries 5: $339-42$.

Nelson, K. 1986. Labor demand, labor supply and the suburbanization of low-wage office work. In Production, work, territory: The geographical anatomy of industrial capitalism. Ed. Allen J. Scott and Michael Storper. Boston: Allen \& Unwin, 149-68.

$\mathrm{Ng}$, Cecillia, and Jamilah Othman. 1991. Occupational health and safety among office workers: A preliminary study. In Safety at work in Malaysia. Ed. Colin Nicholas and Arne Wangel. Kuala Lumpur: Univ. of Malaya, 39-54.

Office of Technology Assessment. 1985. Automation of America's offices, 1985-2000. Washington, D.C.: OTA.

Olsen, Mark, and Alice Music McLean. 1993. Optical character scanning: A discussion of efficiency and politics. Computers and the humanities 27: 121-27.

Pearson, Ruth. 1992. Global information processing: The emergence of software services and data entry jobs in selected developing countries. Sectoral activities program, working papers. Geneva: International Labor Office.

- 1993. New technologies and labor segmentation. In Women and change in the Caribbean. Ed. Janet Momsen. London: James Currie; Bloomington: Indiana Univ. Pr., 287-95.

Pearson, Ruth, and Swasti Mitter. 1993. Employment and working conditions of lowskilled information-processing workers in less developed countries. International labour review 132: 49-64.

Posthuma, Annie. 1987. The internationalization of clerical work: A study of offshore office services in the Caribbean. SPRU occasional paper series, no. 24. Brighton, U.K.: Science Policy Research Unit.

Saffady, William. 1995. Digital library concepts and technologies for the management of library collections: An analysis of methods and costs. Library technical reports 35: 221-380.

Shiga, Hiroko. 1987. Microelectronics and women in Japan. In Technology and gender: Women's work in Asia. Ed. Cecilia Ng. Kuala Lumpur: Women's Studies Unit (Universiti Pertania Malaysia) and Malaysian Social Science Assoc., 84-91.

Sores, Angelo A. 1991. The hard life of the unskilled workers in new technologies: Data-entry clerks in Brazil: A case study. Human aspects in computing: Design and use of interactive systems and information management: Proceedings of the Fourth International Conference on HumanComputer Interaction, Stuttgart, F.R. Germany, September 1-6, 1991. Ed. H. J. Bullinger. Vol 2. Amsterdam: Elsevier, 1219-23.

Sugal, Cheri. 1996. Labeling wood: How timber certification may reduce deforestation. World watch (Sept./Oct.): 29-34.

Trade Act of 1974. 1994. U.S. Code. Vol. 9, sec. 2462.

Warf, Barney. 1995. Telecommunications and the changing geographies of knowledge transmission in the late 20th century. Urban studies 32 : 361-78.

Young, Jeffrey R. 1996. Modern-day monastery. Chronicle of higher education (Jan. 19): A21-A22. 